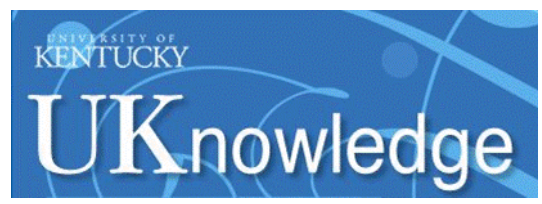

University of Kentucky

UKnowledge

\title{
Online Story Comprehension among Children with ADHD: Which Core Deficits are Involved?
}

\author{
Kate Flory \\ University of South Carolina - Columbia, floryk@mailbox.sc.edu \\ Richard Milich \\ University of Kentucky, richard.milich@uky.edu \\ Elizabeth P. Lorch \\ University of Kentucky, elorch@uky.edu \\ Angela N. Hayden \\ University of Kentucky, anhayd1@uky.edu \\ Chandra Strange
}

See next page for additional authors

Follow this and additional works at: https://uknowledge.uky.edu/psychology_facpub

Part of the Child Psychology Commons

Right click to open a feedback form in a new tab to let us know how this document benefits you.

\section{Repository Citation}

Flory, Kate; Milich, Richard; Lorch, Elizabeth P.; Hayden, Angela N.; Strange, Chandra; and Welsh, Richard, "Online Story Comprehension among Children with ADHD: Which Core Deficits are Involved?" (2006).

Psychology Faculty Publications. 2.

https://uknowledge.uky.edu/psychology_facpub/2

This Article is brought to you for free and open access by the Psychology at UKnowledge. It has been accepted for inclusion in Psychology Faculty Publications by an authorized administrator of UKnowledge. For more information, please contact UKnowledge@lsv.uky.edu. 
Online Story Comprehension among Children with ADHD: Which Core Deficits are Involved?

Digital Object Identifier (DOI)

$10.1007 / \mathrm{s} 10802-006-9070-7$

Authors

Kate Flory, Richard Milich, Elizabeth P. Lorch, Angela N. Hayden, Chandra Strange, and Richard Welsh 
Running Head: ONLINE STORY COMPREHENSION

Online Story Comprehension among Children with ADHD:

Which Core Deficits are Involved?

\author{
Kate Flory \\ University of South Carolina \\ Richard Milich, Elizabeth P. Lorch, \\ Angela N. Hayden, Chandra Strange, \& Richard Welsh \\ University of Kentucky
}

Journal of Abnormal Child Psychology, in press 


\begin{abstract}
Children with ADHD have difficulty understanding causal connections and goal plans within stories. This study examined mediators of group differences in story narrations between children ages 7-9 with and without ADHD, including as potential mediators both the core deficits of ADHD (i.e., inattention, disinhibition, planning/working memory) as well measures of phonological processing and verbal skills. Forty-nine children with ADHD and 67 non-referred children narrated a wordless book and completed tasks assessing the core deficits of ADHD, phonological processing, and verbal skills. Results revealed that, although no shorter than those of non-referred children, the narratives of children with ADHD contained fewer elements relating to the story's causal structure and goal plan. Deficits in sustained attention accounted for the most variance in these differences. Results have implications for understanding and ameliorating the academic problems experienced by children with ADHD.
\end{abstract}

KEY WORDS: Story comprehension; ADHD; core deficits; inattention 


\section{Online Story Comprehension among Children with ADHD:}

Which Core Deficits are Involved?

Attention deficit hyperactivity disorder (ADHD) historically has been understood as a collection of core etiological deficits, which include problems with planning ahead, paying attention, and inhibiting inappropriate behavior. The identified core deficits of ADHD essentially have remained the same since the second edition of the Diagnostic and Statistical Manual of Mental Disorders (DSM-II; American Psychiatric Association, 1968). Over this time period, however, theories have varied as to which of the core deficits plays the major role in accounting for the problems experienced by children with ADHD.

One theoretical direction is represented by the seminal research of Virginia Douglas (1983). Although Douglas's model incorporated several components, including disinhibition and dysregulation difficulties, her model shifted focus away from hyperactivity toward the problems in sustaining attention to tasks exhibited by children with ADHD. In fact, her research in this area was a major impetus for the "radical reconceptualization" (Barkley, 1998, p. 21) of the disorder as primarily an attention deficit (DSM-III, 1980). Over the following decade, a wealth of research tried to elucidate the nature of the attention problems exhibited by children with ADHD.

If the 1980s were devoted to understanding deficits in attention, the guiding theories of the 1990s focused on the disinhibitory problems of children with ADHD. Quay (1988) argued that the core deficit of children with ADHD is a deficient behavioral inhibitory system. Barkley's (1997) elaborated model specifies problems in disinhibition as the primary or core deficit of ADHD. In this model, other problems exhibited by children with ADHD, including their attention deficits, are viewed as secondary and arising from deficits in disinhibition.

With recent developments in neuropsychological testing and advanced neuroimaging 
procedures, theoretical attention has been directed toward conceptualizing ADHD as a deficit in executive functioning (EF) (Barkley, 1998; Nigg, 2001). Although these theories are still in their early stages, EF disorders have been characterized in at least two distinct fashions. On the one hand, executive functioning deficits have been conceptualized broadly, to subsume many of the problems exhibited by children with ADHD, including inattention, disinhibition, poor planning, and deficient working memory (Barkley, 1997). Such an approach tends to be concerned with the cognitive regulation of behavior in general (Giancola, 2000). Alternatively, executive functioning deficits can be specified more narrowly, focusing on specific higher order functions such as strategic goal planning. This approach is more concerned with the individual components that make up the broader regulatory process (Giancola, 2000). However conceptualized, evidence is emerging that children with ADHD reliably exhibit deficits in executive functioning (Nigg, 2001).

As this brief review indicates, at least three different theoretical approaches have guided research on ADHD over the past three decades, and at times even have influenced diagnostic criteria (e.g., ADD vs. ADHD). In addition, numerous studies have been undertaken to determine which of these core deficits (i.e., inattention, disinhibition, EF deficits) best differentiates children with ADHD from comparison groups (e.g., Nigg, Blaskey, Huang-Pollock, \& Rappley, 2002; Pennington, Grossier, \& Welsh, 1993). However, what is missing from this research are studies that examine the extent to which each of these core deficits accounts for the academic or social impairments experienced by these children. It may be that no one theoretical approach is adequate to account for the many problems exhibited by children with ADHD, and that different core deficits account for different aspects of the academic and social impairments associated with ADHD (e.g., inattention for academic problems, disinhibition for social difficulties). 
The present study seeks to address this gap in the ADHD literature by directly examining which of the core deficits of ADHD account for some of the academic difficulties experienced by children with the disorder. Specifically, we compare children ages 7-9 with ADHD to nonreferred children on story comprehension, a higher-order academic skill, which has been welldocumented as a deficit of children with ADHD (Milich, Lorch, \& Berthiaume, 2005). More importantly, we examine which of the core deficits of ADHD (i.e., problems with inattention, disinhibition, or the EF components of planning and working memory ${ }^{1}$ ) best account for the deficits in story comprehension of children with the disorder.

Although our primary interest was to examine the contribution of the core deficits of ADHD, as important contrasts we also explored the roles of phonological processing ability and verbal skills in the story comprehension problems of children with ADHD. A link between deficits in phonological processing and reading impairment has been well established (e.g., Bruck, 1988; Purvis \& Tannock, 2000; Wagner \& Torgesen, 1987), as has a link between reading impairment/disability and $\mathrm{ADHD}$, which co-occur at a rate of $13 \%$ to $38 \%$ percent (e.g., Faraone et al., 1993; Semrud-Clikeman, Biederman, Sprich-Buckminster, Lehman, Faraone, \& Norman, 1992). Although the present study utilized a story comprehension measure that did not rely directly on reading ability, it still is possible that comorbid reading disability accounts for the problems in story comprehension seen among children with the disorder. In addition, prior research (e.g., Andreou, Agapitou, \& Karapetsas, 2005) has suggested that children with ADHD have poorer verbal skills than do control children. Because our story comprehension measure required children to verbally narrate a story, it is possible that children's verbal skills could explain group differences in story comprehension outcomes. Thus, including measures of phonological processing ability and verbal skills allowed us to contrast the contribution of the 
core deficits of ADHD with the contribution of reading impairment and verbal ability. These contrasts have important implications for elucidating exactly why children with ADHD have difficulties in story comprehension.

\section{Theories of Story Comprehension}

To comprehend a story, children must be able to recognize what is important to the story and to organize this information in a way that makes it understandable (van den Broek, 1989). Two prominent theories of story comprehension incorporate these ideas. Story grammar theory (Mandler \& Johnson, 1977) maintains that some aspects of a story are more important and better remembered than others. Stories begin with an initiating event that causes the main character to establish an overall goal. This is followed by an attempt to achieve the goal. In a hierarchal goal structure, where some goals are more important than others, this initial attempt fails to complete the overall goal, which creates subgoals and spurs further attempts. The final attempt results in the main character achieving the overall goal. According to story grammar theory, these goalattempt-outcome (GAO) sequences are the most important idea units in a story and thus are better remembered than other aspects of the story (Mandler \& Johnson, 1977; Nezworski, Stein, \& Trabasso, 1982).

The causal network model, proposed by Trabasso and colleagues (i.e., Trabasso \& Sperry, 1985; Trabasso \& van den Broek, 1985), extended the story grammar theory by suggesting that recall depends upon the extent to which an idea unit is connected to other ideas in the story. Recall for an idea unit in a story increases with the number of causal connections it has (O’Brien \& Myers, 1987; Trabasso \& Sperry, 1985). Goals generally have the highest number of causal connections and thus are best recalled (Nezworski et al., 1982; Trabasso \& van den Broek, 1985). 


\section{Online Narration}

By assessing recall, many studies of story comprehension not only explore knowledge of causal connections and goal plans, but also test children's memory. Thus, although memory deficits are hypothesized to be an integral aspect of ADHD (Barkley, 1998), researchers have attempted to tease out the effects of memory on comprehension by using a narrative approach in which a child is asked to tell a story from a wordless picture book. This online (i.e., occurring during story processing) narration task reduces memory demands because an element of the story is available to the child at all times. However, in order to narrate the story coherently, the child needs to understand the importance of a goal plan in resolving the dilemma in the story (Trabasso, Stein, Rodkin, Munger, \& Baughn, 1992). The child also needs to grasp the importance of causal connections to establish why one event follows another. A narration missing these elements is indicative of deficits in story comprehension.

\section{Online Narration/Comprehension among Children with ADHD}

Only two studies were identified that specifically have examined the online story comprehension of children with ADHD. Milch-Reich, Campbell, Pelham, Connelly, and Geva (1999) investigated story narration among school-aged children with ADHD and nonreferred children. Children narrated a series of seven pictures and the organizational structure of the narratives was examined. Non-referred children and children with ADHD included the same number of ideas in their narratives but children with ADHD produced narratives that contained fewer causal connections, and they made more errors in their narrations than non-referred children.

The Milch-Reich et al. (1999) study demonstrated that children with ADHD and nonreferred children differ in their ability to organize a story and in their understanding of causal 
connections. However, the story used in this study only contained seven pictures with no hierarchical goal structure. In order to truly capture differences in the cohesion and organization of online narrations, a longer, more elaborate story is needed. Story-grammar theory provides an explicit technique for examining understanding of causal connections and goal-based categories, which are important in the cohesion and organization of a story.

To this end, Renz, Lorch, Milich, Lemberger, Bodner, and Welsh (2003) used both a longer story and the story grammar coding categories in order to explore differences in online narrations between 9- to 11-year-old children with ADHD and their non-referred peers. The story used by Renz et al. (2003), Frog Where Are You? by Mercer Mayer (1969), contains 24 pictures and includes a hierarchical goal structure. The story begins with a frog escaping from its owner, a little boy, which establishes his overall goal of finding the frog and bringing it back home. A number of unsuccessful attempts to meet the goal create subgoals. Ultimately, the boy does succeed in resolving his overall goal of bringing a frog back home.

In their study, Renz et al. (2003) coded the children's narratives for the establishment of the overall goal, the subsequent subgoal attempts and outcomes, and the resolution to the overall goal. The subgoal attempts were classified into unlinked attempts (i.e., not explicitly related to finding the frog), linked attempts (i.e., specifying the overall goal of finding the frog), and specific linked attempts (i.e., when the boy searched specific locations for the frog). Linked attempts suggest an understanding of both goal structure and causal connections because the child restates the boy's goal of searching to recover the frog, which was established at the beginning of the story.

Renz et al. (2003) found that non-referred children included the resolution of the overall goal significantly more often than children with ADHD, suggesting that non-referred 
children ages 9 to 11 are better able to maintain a goal plan throughout the narration of a story. Children with ADHD also used fewer specific linked attempts than did non-referred children. This suggests that children with ADHD have a less developed understanding of goal plans and their narratives lack cohesion and organization compared to their non-referred peers. Finally, children with ADHD made more errors in their narrations than did non-referred children. Specifically, children with ADHD repeated themselves more often and they used more ambiguous references within their sentences.

Although the Renz et al. (2003) study is important to understanding the organization of narratives of children with $\mathrm{ADHD}$, the age range of children within the study may not have captured major developmental changes in story comprehension. According to Trabasso et al. (1992), the most important ages for the development of the understanding of causal structure and goal plan are between 3 and 9. Thus, in the present study, the methodology of Renz et al. (2003) was used to examine goal structure in story narrations of 7- to 9-year-old children with and without ADHD.

\section{The Current Study}

In sum, the main purpose of the present study is to examine which of the core etiological deficits of ADHD (i.e., inattention, disinhibition, or the EF components of planning and working memory) account for the online story comprehension difficulties of children with ADHD. A second purpose is to contrast the influence of the core deficits of ADHD on story comprehension with the contributions of deficits in phonological processing and verbal skills. A final purpose of the study is to extend the Renz et al. (2003) online story narration methodology to a younger (ages 7-9) cohort of children. Based on prior research with older children, we predict that children with ADHD will produce story narrations including fewer goal-based events 
and more errors than non-referred children. Further, we predict that group differences in the use of goal-based events will be accounted for best by the EF components of planning and working memory, because these components are necessary to sustain the goal plan throughout the narration. Conversely, we predict that group differences in story-narration errors will best be accounted for by the core deficit of disinhibition, because errors often are due to impulsive responding (Milch-Reich et al., 1999). Finally, considering previous research findings, we predict that children with ADHD will demonstrate greater deficits in phonological processing ability and verbal skills than non-referred children. However, we do not believe that these deficits will fully explain the story comprehension problems of children with ADHD.

Method

\section{Participants}

The sample included children ranging in age from 7 to 9 ( $M$ age $=8$ years, 5 months). This group included 49 children with ADHD (80\% boys) and 67 non-referred children (64\% boys). Eighty-five percent were Caucasian, $11 \%$ were African American, and $4 \%$ were from another ethnic group (e.g., Asian, Hispanic). There were no differences between the two diagnostic groups (ADHD and non-referred) on age, $F(1,113)=.28, p=.57$ (see Table 1 for means). However, there were significantly more non-Caucasian children in the ADHD group than in the non-referred group, $\chi^{2}(2, N=116)=7.23, p<.05$, effect size $r=.25$, and a trend toward more boys than girls in the ADHD group than in the non-referred group, $\chi^{2}(1, N=116)=$ $3.25, p=.07, r=.17$. In addition, both mothers and fathers of children in the ADHD group reported a lower educational status than parents of non-referred children (for mothers, $F(1,112)$ $=25.57, p<.01, r=.43$; for fathers, $F(1,105)=27.53, p<.01, r=.46)$.

Children with ADHD were recruited from a university psychiatric clinic where they had 
been diagnosed with ADHD/Combined type by a psychiatrist or other mental health professional. Children who exhibited only attentional problems were not contacted for participation in the study because of mounting evidence of differences between the predominantly inattentive and combined groups indicating the inattentive group may be a distinct disorder and not a subtype of ADHD (Milich, Balentine, \& Lynam, 2001). Children also were not contacted for participation if they were currently taking psychiatric medications that could not be withheld safely on the days of the study. Thus, psychostimulant medications were allowed, and $90 \%$ of the ADHD group participants were taking these medications at the time of the study.

In order to confirm each child's ADHD diagnosis, a semi-structured interview was conducted with his or her parent or caregiver (typically the mother) on the first day of the study. A trained doctoral student conducted each of the interviews, which consisted of items corresponding verbatim to the DSM-IV (1994) ADHD diagnostic criteria. Parents were asked whether their child exhibited each ADHD symptom, and if so, to give an example of the child's symptomatic behavior. The parents also were asked whether they believed their child's behaviors to be age-appropriate and whether the behaviors impaired school or social performance. A symptom only was considered present if the parent indicated the behavior was age-inappropriate and impairing. This interview procedure has been used successfully by this research group in previous studies, with interrater reliabilities for the number of ADHD symptoms endorsed by the parent above $95 \%$ (e.g., Lorch et al., 1999). Any child who did not meet the DSM-IV (1994) ADHD/Combined type diagnostic criteria (i.e., parents endorsed 6 or more symptoms of hyperactivity/impulsivity and 6 or more symptoms of inattention) during this interview was excluded from further participation in the study. Forty-three percent of children in the ADHD 
group also met $D S M-I V$ (1994) diagnostic criteria for ODD (i.e., parents endorsed 4 or more symptoms). Children with ADHD were medication-free on the days of testing.

Non-referred children were recruited by advertisements in several local newspapers and flyers distributed at various community locations. Interested parents initially were screened over the phone for whether their child had a history of behavior, learning, or attention problems. Parents of non-referred children also completed the DSM-IV (1994) interview during the first session of the testing to verify non-ADHD status, and children who met three or more criteria for ADHD or ODD were excluded from further participation in the study. Thus, the comparison children were not required to be symptom free, but were significantly less symptomatic than children in the ADHD group with respect to DSM-IV (1994) ADHD and ODD symptoms (see Table 1$), F(1,112)=1317.98, p<.01, r=.96$ and $F(1,112)=91.90, p<.01, r=.67$, respectively. Both groups of children were further assessed by having one parent complete the Child Behavior Checklist (CBCL; Achenbach, 1991). Comparison children scored significantly lower than children with ADHD on the Attention Problems scale and the Internalizing and Externalizing factors of this measure, $F(1,112)=431.96, p<.01, r=.89, F(1,110)=45.15, p<$ $.01, r=.54$, and $F(1,111)=101.75, p<.01, r=.69$, respectively (see Table 1 for means).

Parental consent for the study was obtained prior to each child's participation. Children completed three testing sessions approximately two weeks apart, with each lasting approximately one and a half hours. In order to maintain participants' interest and motivation during the testing sessions, the children were offered frequent breaks, tasks were interspersed within sessions such that the child did not participate in two similar tasks in a row, and children were allowed to choose a small toy at the beginning and end of each testing session. Participating families were paid $\$ 15$ for each session and an additional $\$ 15$ for completing all three sessions. 


\section{Procedure}

The online story comprehension task was conducted during the second testing session. Two different stories were used for this task, both wordless picture books and both by Mercer Mayer. Frog Where Are You? (Mayer, 1969) was used by both Renz et al. (2003) and Trabasso et al. (1992) and the plot of the story, including the overall goal and subgoals, is described in the introduction. The second story, A Boy, A Dog, and A Frog (Mayer, 1967), is the prequel to Frog Where Are You? and also contains a series of 24 pictures. In this story, a boy sees a frog while fishing with his dog, which is the initiating event that sets up the overall goal of trying to catch the frog for a pet. When the boy fails to catch the frog in his first attempt, this prompts further attempts (subgoals). After several more futile attempts to catch the frog, the boy gives up and walks home with his dog. The frog then appears to be lonely without the boy and follows the boy's footprints home. The frog eventually finds the boy taking a bath and jumps in, thus providing a positive resolution to the boy's overall goal of catching the frog as a pet.

During the story narration task, children were tested individually and were seated across from an experimenter blind to the purpose of the study and the child's diagnostic group. A binder containing one of the two stories, chosen randomly, was placed in front of the child and the experimenter said, "This is a book that tells a story. This story only has pictures. You have to make up the words for the story. Start with the first picture, and for each of the pictures, tell me the story. Make sure you make up a part of the story for each of the pictures in the book." The child then told the story to the experimenter, picture by picture. If any pictures were skipped, the experimenter pointed at the picture, saying "tell me about this picture." The child was given as much time as needed to complete the story and each narrative was audio and video recorded for later coding. 


\section{Story Comprehension Measures}

Narratives were transcribed verbatim from the recordings. Two trained coders blind to the child's diagnosis parsed the narratives into discrete story units (i.e., single ideas or events from the story), which then were coded based on the story grammar categories designated by Mandler and Johnson (1977). Inter-rater reliability averaged above .80 across coding categories. For the present study, we only examined errors and the coding categories, described below, directly related to the goal structure of the story.

Initiating event. The initiating event sets up the overarching goal of the main character. For instance, in Frog Where Are You?, the initiating event is when the boy finds that the frog has escaped from his jar, establishing the boy's goal of finding the frog and bringing it back home. This variable was coded as to whether the child did (1) or did not (0) mention the initiating event.

Attempts and outcomes. In most stories, attempts to complete the goal generally follow statement of the initiating event. Three types of attempts were coded in the children's narratives. An unlinked attempt is unrelated to the goal sequence because there is no mention of the overall goal. An unlinked attempt was coded if the child explained that the boy was looking, calling, or trying to catch, but didn't state what his goal was in doing these behaviors. A linked attempt was coded if the child explained the boy's goal of trying to find/catch the frog (e.g.,"The boy looks for the frog"). A specific linked attempt was coded if the child explained that the boy was searching or calling for or trying to catch the frog in a specific location (e.g., "The boy looked for the frog in the hole"). These three variables were each coded as the total number of attempts stated by the child.

In both stories, most of the boy's attempts to find or catch the frog end in negative 
outcomes, as the boy repeatedly is unsuccessful at meeting his goal. This variable was coded as the total number of negative outcomes stated by the child. The final attempt to find or catch the frog in each story ends in a positive outcome. This variable was coded as to whether the child did (1) or did not (0) mention the final positive outcome.

Goal-attempt-outcome (GAO) sequences and goal completion. Linked attempts followed by a positive or negative outcome constitute a GAO sequence. GAO sequences are vital to the story because they represent the essential elements of goal structure. Narratives that include many GAO sequences are generally more organized and cohesive than those with few sequences. This variable was coded as the total number of positive and negative outcomes.

One of the most important aspects of goal structure is generally found at the end of a story. Goal completion is the resolution to the overall goal of trying to find or catch the frog (e.g., "The boy got to keep one of the little frogs and bring it home"). This variable was coded as to whether the child did (1) or did not (0) state the completion of the overall goal.

Errors. Narratives also were coded for three different categories of errors. Within clause errors were coded when part of a child's clause was unclear or ambiguous, such as "The little boy looked there" ("there" does not refer to a specific location). A whole clause error was coded when a child stated an event that either did not occur in the story (e.g., "The boy killed the frog") or occurred in a different order than was stated. Repetition errors were coded when the child restated an idea from a previous picture when it was not occurring in the present picture.

\section{Measures of the ADHD Core Deficits}

The two tasks measuring the core deficits of ADHD were conducted during the first two testing sessions and were interspersed with additional tasks not included in the present study. These tasks were administered individually by an experimenter blind to the child's group status. 
Tower of London-Drexel $\left(T O L^{D X}\right)$ task. Each child completed the $\mathrm{TOL}^{\mathrm{DX}}$ task (Culbertson \& Zillmer, 2000), which Barkley (1997) describes as a measure of EF planning and working memory. The task uses two identical wooden tower structures with three pegs of descending height. Each structure contains three different colored beads placed on the pegs in a prescribed starting order. One structure is placed in front of the child and the other in front of the examiner. The examiner then arranges the pegs in a new pattern and the child attempts to copy the pattern by moving his or her beads from peg to peg one at a time. The task consists of 10 bead problems of increasing difficulty. After each problem, the pegs on both structures are returned to the starting positions.

In explaining the instructions for the $\mathrm{TOL}^{\mathrm{DX}}$, the child was informed of two rules: (1) do not place more beads on a peg than it will hold, and (2) move only one bead at a time. The experimenter demonstrated each type of rule violation. The child then solved two practice problems, was reminded of the instructions and that each problem could be solved. The child was to copy each bead pattern in as few moves as possible. All items required between two and seven moves. The child was reminded of the rules any time that he or she attempted to violate them and only one trial was allowed for each of the problems. Performance on each trial was timed.

The $\mathrm{TOL}^{\mathrm{DX}}$ was scored based on its standard instructions. For the present study, five variables from the instrument were standardized and combined to form a composite measure of the EF components of planning and working memory $(\alpha=.88)$. The variables, which were moderately to strongly correlated (with $r$ 's ranging from .43 to .97 ), included number of problems solved correctly (reversed), number of moves, execution time, total time, and rule violations. Each variable was obtained by summing the child's scores for all 10 problems. 
Number of moves was calculated by subtracting the number of moves necessary to create the target pattern from the number of moves the child actually made. A move was counted each time a bead left a peg, even if it was returned to the same peg. Execution time for each problem was the amount of time that elapsed between when the child moved the first bead and when he or she completed the target pattern. Total time was the amount of time between when the child was presented with the problem and when he or she completed the target pattern, and was capped at two minutes. If a child gave up on a problem before the time was up, a total move score of 20 was recorded. Finally, rule violations were counted.

Stop signal task. Each child completed a Stop signal task (Schachar \& Logan, 1990), which assesses attention and disinhibition. This task measures the child's ability to respond correctly and quickly to go-signals and to inhibit his or her responses when presented with stopsignals. The task is presented on a computer and consists of three parts. The first two parts each include 88 trials and are used to establish the child's baseline mean reaction time (RT) and to familiarize him or her with the task. The third part of the task consists of 176 trials and produced the data used in the analyses.

For all three parts of the task, the child was seated in front of the computer and instructed to place his or her first two fingers of the dominant hand on the " 1 " and " 3 " on the numeric keypad and to focus on the middle of the screen. For the task, the " 1 " key was marked with an "X" on the top and side of the key, whereas the " 3 " key was marked with an "O". When the experimenter began the task, a succession of X's and O's were presented on the computer screen one at a time in random order. The child was instructed to press the appropriate key as quickly as possible after the stimuli were presented. Periodically, a tone (stop-signal) was heard after the presentation of the stimuli. When this happened, the child was instructed to try not to press the $\mathrm{X}$ 
or O key. However, the child also was instructed not to delay his or her responses to the gosignals to wait for the stop-signals. The program recorded errors, but they did not affect the presentation of the stimuli, and children were not informed of their mistakes or performance results during the task.

In the first part of the task, the child was instructed to ignore the tones and to respond to each of the presented stimuli. This part of the task produced a baseline mean RT in milliseconds that then was used by the examiner during a short break to program the stop-signals for the child for the second and third parts of the task. During the second part of the task, the child was instructed to attend to the stop-signals and to attempt to inhibit his or her responses when a stopsignal was presented. This part of the task was designed to familiarize the child with the instructions and no data were collected.

The data were collected during the third part of the task, during which there were 50 stopsignals randomly distributed within the 176 trials. The stop-signals occurred at five different lengths of time after the presentation of the go-stimuli. The signals are more difficult to respond to the further they are from the stimuli, but were presented in a random order throughout the task. The signal furthest from the stimuli was equivalent to the child's baseline mean RT, whereas the stop-signal closest to the stimuli was the baseline mean RT minus 400 milliseconds. The stop-signals between the furthest and closest to the stimuli were each 100 milliseconds less than the prior signal.

The stop-signal task was scored based on standard instructions. Five variables collected during the third part of the task were used in the present study. The standard deviation of RTs to all go-signals and the number of go-signals not responded to (i.e., errors of omission) were standardized and combined $(r=.72)$ to represent inattention (see Castellanos \& Tannock, 2002). 
The number of errors made on go-signal trials (i.e., pressing $\mathrm{X}$ when $\mathrm{O}$ should have been pressed; errors of commission) and the numbers of stop signals not responded to for the two signals presented closest to the $\operatorname{stimuli}^{2}$ ( $r$ s ranged from .53 to $.76 ; \alpha=.84$ ) were standardized and combined to represent disinhibition.

Measure of Phonological Processing

Phoneme segmentation task. This task is a 16-item measure of phonological processing that requires the child to repeat a nonsense word after eliminating a specific sound. For example, the child is asked to say 'teb' and then asked to say it without the ' $t$ ' sound. Prior research (Purvis \& Tannock, 2000) has demonstrated that children with reading disability (with or with comorbid ADHD) perform more poorly on phonological processing tasks than children without a reading disability. For the present study, the task was individually administered during the third testing session by an experimenter blind to the child's group status. Using one of three counterbalanced forms, the experimenter read each item aloud and waited for the child's response. The total number of items correct was used to represent phonological processing ability.

\section{Measure of Verbal Skills}

Wechsler Intelligence Scale for Children, $3^{\text {rd }}$ edition (WISC-III). Children were given the WISC-III (Wechsler, 1991) vocabulary subtest during the first session by an experimenter blind to the child's group status. The scaled score for this subtest, which has been shown to significantly differentiate children with ADHD from control children (Andreou et al., 2005), was used to represent verbal skills.

Results

Analyses proceeded in three steps. First, a series of one-way analyses of variance was 
conducted in order to examine diagnostic group differences on each of the story coding categories. The $F$ test has been shown to give accurate results for dichotomous variables (Rosenthal \& Rosnow, 1991), thus was used for all coding categories for simplicity of presentation. Second, the same analyses were undertaken to determine group differences on the core deficits of ADHD, on phonological processing ability, and on verbal skills. Third, for those story narration variables for which group differences were found, mediation analyses were undertaken to determine the degree to which the three core deficits, phonological processing ability, and verbal skills accounted for these group differences.

\section{Group Differences on Story Coding Categories}

There were no differences between the ADHD and non-referred groups on the average number of clauses children included in their stories, $F(1,114)=.11, p=.74$. However, there were group differences on several of the coding categories related to the causal structure of the stories and on all three error categories (see Table 2).

Initiating event. There was a significant group difference for the statement of the initiating event, $F(1,114)=7.54, p<.01$, effect size $r=.25$. Of the non-referred children, $84 \%$ mentioned this event in their narratives, whereas only $63 \%$ of children with ADHD included the event.

Attempts. There were no significant group differences in the number of unlinked attempts, $F(1,114)=1.66, p=.20$, linked attempts, $F(1,114)=1.96, p=.16$, or specific linked attempts, $F(1,114)=1.40, p=.24$, children included in their stories.

Outcomes. There was no significant group difference on number of negative outcomes children included in their narratives, $F(1,114)=1.70, p=.20$. However, significantly fewer children with ADHD (61\%) mentioned the final positive outcome then did non-referred children 
$(78 \%), F(1,114)=4.46, p<.05, r=19$.

GAO sequences. There was a marginally significant group difference in the number of GAO sequences children included in their narratives, $F(1,114)=3.37, p<.07, r=.17$. Children with ADHD included an average of 2.71 GAO sequences in their stories, whereas non-referred children included an average of 3.21 sequences.

Goal completion. There was a marginally significant group difference for the statement of the completion of the overall goal, $F(1,114)=2.74, p=.10, r=.15$. Only $43 \%$ of children with ADHD mentioned the completion of the goal, whereas $58 \%$ of non-referred children stated the goal's completion. Although only marginally significant, such a difference replicates the results for this category from Renz et al. (2003).

Errors. There were significant group differences on the number of within clause, $F(1$, $114)=5.78, p<.05, r=.22$, whole clause, $F(1,114)=6.53, p<.05, r=.23$, and repetition errors, $F(1,114)=4.72, p<.05, r=.20$, children made when telling their stories. Children with ADHD averaged more of each type of error than did non-referred children (see Table 2).

To address the diagnostic group differences noted in the Participants section, we included gender, race, and mother's educational status as covariates in our analyses looking at diagnostic group differences on the story coding variables. Separate analyses were conducted for each potential covariate in order to estimate independent effects. Neither gender nor mother's educational status was a significant covariate for any of the coding variables that distinguished the groups. Race was a significant covariate for two dependent variables; however, including race as a covariate did not change the pattern of group differences previously noted. Thus, for clarity, we chose to present the analyses without this covariate.

In sum, despite producing stories of similar lengths, children with ADHD told stories that 
were significantly and qualitatively different from those told by non-referred children. Namely, the narratives of children with ADHD included fewer elements relating to the causal structure and goal plan of the story. Children with ADHD were less likely to mention the initiating event that set up the overall goal as well as the positive outcome of attempts to meet the goal, and were more likely to make errors when telling their stories. They also were less likely to include goalattempt-outcome (GAO) sequences in their narratives and to mention the completion of the overall goal.

Group Differences on Core Deficits of ADHD, Phonological Processing Ability, and Verbal Skills

Children with ADHD differed from non-referred children on all three measures of the core deficits of ADHD, on phonological processing ability, and on verbal skills. Children with ADHD $(M z$ score $=1.89)$, compared to non-referred children $(M z$ score $=-1.21)$, demonstrated poorer EF planning and working memory abilities, as measured by the composite $\mathrm{TOL}^{\mathrm{DX}}$ variable, $F(1,108)=16.85, p<.01, r=.13$. Children with ADHD $(M z$ scores $=1.30,1.12)$ also demonstrated more problems with inattention and disinhibition, as measured by composites from the stop signal task, than did non-referred children $(M z$ scores $=-.85,-.73), F(1,104)=49.89, p$ $<.01, r=.32$ for inattention and $F(1,104)=14.33, p<.01, r=.12$ for disinhibition. In addition, children with ADHD $(M$ score $=7.04)$, compared to non-referred children $(M$ score $=11.39)$ demonstrated poorer phonological processing ability, as measured by the phoneme segmentation task, $F(1,111)=31.78, p<.01, r=.47$. Finally, children with ADHD $(M$ score $=8.91)$, compared to nonreferred children $(M$ score $=13.34)$, also demonstrated poorer verbal skills as measured by the WISC-III vocabulary subtest, $F(1,108)=38.64, p<.01, r=.51$.

\section{Mediation Results}


The statistical procedure used to test for mediation was the product of coefficients approach recommended by MacKinnon and colleagues in a recent article that compared different methods of testing for mediation (MacKinnon, Lockwood, Hoffman, West, \& Sheets, 2002). In this procedure, a series of regression analyses are conducted in which the mediating variable is regressed on the independent variable, and the dependent variable is regressed on both the independent and mediating variables. Then, the regression coefficients representing the IVmediator $(\alpha)$ and mediator-DV $(\beta)$ links are converted into $z$ scores, and the product of the two $z$ scores is compared against the distribution of the product of two normal random variables (MacKinnon et al., 2002), with the critical value of the distribution for $p<.05$ being 2.18 . The results of the mediation analyses are presented in Table 3 . The results displayed in the first three columns (i.e., the $\mathrm{z}$ scores) are from analyses with all five mediators entered simultaneously. The percent reduction in the regression coefficient attributable to each mediator is also presented in Table 3. These values are from analyses with each mediator entered individually in order to estimate the independent effect of each mediator. The inattention mediator reached significance in accounting for observed group differences on five out of the seven story coding categories, whereas the EF and disinhibition mediators did not reach significance for any of the seven story coding variables. Generally, these results suggest that the core deficit of inattention plays a large role in the problems children with ADHD have in narrating a coherent, goal-based story. The verbal skills and phonological processing mediators reached significance for three and two of the seven story coding variables respectively, suggesting that these abilities (or lack thereof) also may play a role in explaining the story comprehension difficulties of children with ADHD.

Because of substantial variation in the percent reduction attributable to each mediator, we 
focus only on those mediation analyses in which there was at least a $40 \%$ reduction in the relation between group and the coding category. With this criterion in mind, it is evident that inattention was consistently the most influential of the core ADHD deficits. This measure met the $40 \%$ criterion for four of the seven categories, and, with only one exception (repetition errors), it accounted for the largest percent reduction of all three ADHD core deficits. Despite not being a significant mediator, EF did meet the $40 \%$ criterion in accounting for group differences in GAO sequences. The phonological processing measure met the $40 \%$ criterion for three of the seven categories and the verbal skills mediator met the $40 \%$ criterion for two of the seven categories.

\section{Discussion}

The primary purpose of the present study was to identify the degree to which the core deficits of ADHD (i.e., EF planning/working memory, inattention, and disinhibition) account for the problems that children with ADHD experience in producing coherent story narrations. Employing several different criteria, difficulty sustaining attention clearly was the most influential mediator in accounting for differences in story narrations between children with ADHD and non-referred children. This finding runs counter to current theories that contend that problems sustaining attention are secondary to deficits in executive functioning and behavioral inhibition in accounting for the academic and social impairment experienced by children with ADHD (Barkley, 1997). It may well be that these inhibitory and executive functioning deficits are especially important in accounting for the disruptive, difficult-to-manage behavior associated with this disorder. However, the present results suggest that when encountering complex academic tasks, problems in sustaining attention may become primary.

Perhaps it is not surprising that a measure of sustaining attention would be so critical in 
accounting for the deficits children with ADHD have in story narration. Inconsistent attention clearly would impede focus on maintaining activation of the goal plan that directs the protagonist's actions, thereby making it more likely that children with ADHD would approach a new page in the wordless picture book as a set of discrete events, without necessarily connecting these events to an ongoing story representation. It may be that sustaining attention is a prerequisite for the effective use of planning and working memory in developing a coherent story narration.

It is important to note that the critical role played by deficits in sustaining attention would not be evident in observations of the children's behavior. Casual observations of the children with ADHD who participated in this study revealed that they appropriately sustained attention to the story narration task, and actually produced stories of similar length to those produced by comparison children. This suggests that the attention problems of children with ADHD may in fact be related to the depth of concentration or the depth of information processing (i.e., a qualitative rather than a quantitative difference in attention). It also raises the intriguing question of whether interventions designed to improve sustained attention, such as stimulant medication, would alleviate the problems shown by children with ADHD in producing coherent, goal-based stories. It may be that stimulant medication not only would increase on-task behavior, but also could help children to sustain focus on important elements of the story. Alternatively, it may be that specific instruction in identifying characters' goals and relating those goals to a sequence of actions is necessary to help these children maintain focus on elements necessary to build a coherent story representation (Lorch, Berthiaume, Milich, \& van den Broek, in press).

Although problems sustaining attention proved to be the most potent mediator, initially we predicted that group differences in the use of goal-based events would be accounted for best 
by the EF components of planning and working memory, because these components would be necessary to sustain the goal plan throughout the narration. In addition, we predicted that group differences in story-narration errors would be accounted for best by the core deficit of disinhibition, because errors often are due to impulsive responding. Some support was found for the first of these predictions. Specifically, the only group difference for which the EF composite met the $40 \%$ criterion was the story variable that was most dependent on connecting story events, the inclusion of goal-action-outcome sequences in children's narrations. However, the impact of deficits in executive functioning on group differences in story narration was relatively limited compared to the pervasive impact of problems sustaining attention.

The second purpose was to contrast the influence of the core deficits of ADHD on story narration with the contributions of deficits in phonological processes and verbal skills. Given the relatively large conceptual and diagnostic overlap between reading disorders and ADHD, some have argued that group differences in story comprehension may be accounted for better by basic deficits in phonological processing than by the core deficits of ADHD per se (Purvis \& Tannock, 2000). Similarly, it could be argued that our findings of group differences in story comprehension are due to poorer verbal skills among children with ADHD (Andreou et al., 2005) because our measure of story comprehension involved verbal narration. Although phonological processing and verbal skills in the present study did play a role in accounting for some of the group differences in goal-based story narration, inattention was the most consistent mediator of group differences across the story comprehension categories. As we argued earlier, sustaining attention may be a necessary foundation for any other processes involved in building and narrating a story representation, including phonological processing and verbal skills. The present results suggest that story comprehension deficits exhibited by children with ADHD 
cannot solely be attributed to underlying difficulties in phonological processing or verbal skills.

The third purpose of this study was to expand upon the very limited literature examining online story narrations in children with ADHD. Specifically, the online story narrations of 7- to 9-year old children with ADHD and their non-referred peers were compared, thereby extending the investigation of Renz et al. (2003) to a younger sample of children who represent the age at which use of goal plans typically is established (Trabasso et al., 1992). Renz et al. (2003) found that non-referred children ages 9 to 11 were better able than children with ADHD to maintain a goal plan throughout the narration of a story, as indicated by the more frequent mention of the resolution of the overall goal and specific linked attempts. In addition, children with ADHD made more errors in their narrations than did non-referred children, by repeating themselves more often and using more ambiguous references within their sentences. The results of the current study reveal similar, but more basic difficulties in establishing, sustaining, and completing goal-based story narrations among this younger sample of children with ADHD.

Unlike the older children in Renz et al. (2003), these younger children with ADHD showed deficits in establishing the goal plan as indicated by less frequent mention of the initiating event (e.g., the frog is missing from its jar) that gave rise to the protagonist's goal (e.g., find the frog and bring it home). Whereas the older children's difficulty in sustaining the goal plan was limited to fewer specific linked attempts, the younger children with ADHD showed more global difficulty sustaining the goal plan, as indicated by fewer integrated goal-attemptoutcome (GAO) sequences. The younger children with ADHD also showed more serious problems in completing the goal plan, differing from their non-referred peers not only in overall goal completion (e.g., bringing the frog home) as in Renz et al. (2003), but also in mentioning 
the story's final positive outcome (e.g., finding the frog). Finally, group differences in errors in narration were even more pronounced in this younger sample than in Renz et al. (2003), including more repetitions, more ambiguous references, and more extraneous information not supported by the pictures.

The current pattern of group differences indicates that the online narrations of children with ADHD lack consistent direction by a goal plan and instead are composed of relatively discrete events. Further, this difference cannot be attributed to shorter stories among the children with ADHD, as these children produced stories comparable in length to those of the non-referred children. Instead, this pattern of group differences reflects a less mature grasp of story structure, resulting in less coherent stories among children with ADHD. In fact, some of the differences observed in the current study are consistent with patterns observed in younger, non-referred children (Trabasso et al., 1992). These problems in telling coherent stories can adversely impact the academic functioning of children with ADHD in the early elementary grades.

In the early elementary grades, there are numerous reading-related tasks that children need to master. First, they need to learn basic reading skills, such as decoding and sentence level understanding. As such, the reading materials to which they are exposed are relatively simple and lacking in elaborated structure. However, once they have mastered the basic reading skills, the children are exposed to materials with increased length and complexity that require the children to go beyond mere sentence understanding to connect sentences into a coherent story representation. Finally, within the first few grades of elementary school, children must learn to apply their reading skills to materials other than stories (e.g., social studies texts) in order to understand and retain content information.

The results of the present study suggest that young elementary school children with 
ADHD will have significant difficulties building coherent story representations and extracting the relevant information, even when the task does not demand basic reading skills such as decoding. One could speculate that problems in constructing story representations and extracting relevant information would be even more pronounced if the child also was struggling with basic reading skills, as is frequently evident in children with ADHD. Because the ability to build a coherent story representation is so critical to children's comprehension, the current results suggest that instruction of young children with ADHD needs to focus explicitly on helping them identify the protagonist's goals and motivations, and how story events are linked to these elements.

\section{Limitations and Future Directions}

As in most studies that draw from both clinic and community samples, several sampling issues may have impacted our results. Although we made many efforts to recruit participants into our comparison group who were comparable to those in the ADHD group, significant differences on several demographic variables (e.g., race, maternal education) still emerged. Our groups were limited by those who responded to our recruitment efforts and were interested in participating in the study and thus were not as well matched on these variables as we would have liked. However, including these variables as covariates did not change the pattern of group differences on the outcomes of interest. An additional sampling limitation is that we did not collect teacher reports to verify diagnoses of ADHD; thus it is possible that some children in our ADHD group did not actually meet full $D S M$ criteria for the disorder. However, it is difficult to imagine this affecting the pattern of the story comprehension results, which are quite consistent with prior findings in this area.

In studying the impact of the core deficits of ADHD in accounting for these children's 
impairment, decisions were made about how to operationalize the constructs of inattention, disinhibition, and executive functioning. The measures of the core deficits employed in the present study are widely recognized and well-validated. Nevertheless, they may have methodological limitations, and thus other measures of the constructs may be more valid or may produce different patterns of results.

Similarly, in the present study, as contrasts to the ADHD core deficits, we chose to examine phonological processing and verbal skills as potential mediators. We selected these constructs because of strong theoretical links to ADHD and to story comprehension. As we have demonstrated in this study, multiple skills (i.e., inattention, phonological processing) play a role in the story comprehension difficulties of children with ADHD. Thus, it is quite likely that additional constructs not examined in this study also are crucial to the story comprehension abilities of children with the disorder. For example, although we examined the role of verbal skills, it is possible that related abilities, such as verbal expression, might also play a role in story comprehension, particularly as assessed by online story narration. Future research needs to continue investigation of the story comprehension deficits of children with ADHD, employing multiple measures of the core deficits, and additional contrasting variables, such as verbal expression. In addition, because reading disorder does have a particularly strong conceptual connection to story comprehension, it would be informative to include a reading-disordered comparison group in future studies in this area.

The present study built upon the earlier Renz et al. (2003) paper. Consideration of the results of the two studies suggests group differences in the development of story narration across younger and older samples of elementary school children. Although differences in the patterns of results imply intriguing developmental lags among the children with ADHD, any conclusions 
drawn depend on cross-sectional and cross-study comparisons. In order to understand more definitively the developmental nature of story narration problems among children with ADHD, it is necessary to examine this issue employing a longitudinal design.

In sum, this is the first study of which we are aware that examines the degree to which the core deficits of ADHD account for story comprehension deficits among children with the disorder. Although all three core elements accounted for story comprehension problems to some degree, the difficulty sustaining attention that children with ADHD experience was the most influential component, even when contrasted to measures of language processing and verbal skills. Future research in this area should include similar studies to account for other areas of impairments experienced by children with ADHD, thereby advancing both our understanding of underlying mechanisms of the disorder, as well as offering leads as to more efficacious interventions. 


\section{References}

Achenbach, T.M. (1991). Child Behavior Checklist for ages 4-18. Burlington: University of Vermont Department of Psychiatry.

American Psychiatric Association. (1968). Diagnostic and statistical manual of mental disorders ( $2^{\text {nd }}$ ed.). Washington, DC: Author.

American Psychiatric Association. (1980). Diagnostic and statistical manual of mental disorders ( $3^{\text {rd }}$ ed.). Washington, DC: Author.

American Psychiatric Association. (1994). Diagnostic and statistical manual of mental disorders $\left(4^{\text {th }}\right.$ ed.). Washington, DC: Author.

Andreou, G., Agapitou, P., \& Karapetsas, A. (2005). Verbal skills in children with ADHD. European Journal of Special Needs Education, 20, 231-238.

Barkley, R.A. (1997). ADHD and the nature of self-control. New York: Guilford.

Barkley, R.A. (1998). Attention-deficit hyperactivity disorder: A handbook for diagnosis and treatment ( $2^{\text {nd }}$ ed.). New York: The Guilford Press.

Bruck, M. (1988). The word recognition and spelling of dyslexic children. Reading Research Quarterly, 23, 51-69.

Castellanos, F.X. \& Tannock, R. (2002). Neuroscience of attention-deficit/hyperactivity disorder. Nature Reviews: Neuroscience, 3, 617-628.

Culbertson, W.C., \& Zillmer, E.A. (2000). Tower of London ${ }^{D X}$. Multi-Health Systems Inc: North Tonawanda, NY.

Douglas, V.I. (1983). Attention and cognitive problems. In M. Rutter (Ed.), Developmental neuropsychiatry (pp. 280-329). New York: Guilford.

Faraone, S.V., Biederman, J., Lehman, B.K., Spencer, T., Norman, D., Seidman, L.J., et 
al. (1993). Intellectual performance and school failure in children with attention deficit hyperactivity disorder and their siblings. Journal of Abnormal Psychology, 102, 616-623.

Giancola, P. (2000). Executive functioning: A conceptual framework for alcohol related aggression. Experimental and Clinical Psychopharmacology, 8, 576-597.

Lorch, E.P., Berthiaume, K.S., Milich, R., \& van den Broek, P. (in press). Story comprehension impairments in children with ADHD. In K. Cain and J.V. Oakhill (Eds.), Cognitive bases of children's language comprehension difficulties. New York: Guilford Publications, Inc.

Lorch, E.P., Sanchez, R.P., van den Broek, P., Milich, R., Murphy, E.L., Lorch Jr., R., et al. (1999). The relation of story structure properties to recall of television stories in young children with attention-deficit hyperactivity disorder and nonreferred peers. Journal of Abnormal Child Psychology, 27, 293-309.

MacKinnon, D.P., Lockwood, C.M., Hoffman, J.M., West, S.G., \& Sheets, V. (2002). A comparison of methods to test mediation and other intervening variables. Psychological Methods, 7, 83-104.

Mandler, J.M., \& Johnson, N.S. (1977). Remembrance of things parsed: story structure and recall. Cognitive Psychology, 9, 111-151.

Mayer, M. (1967). A boy, a dog, and a frog. New York: Dial.

Mayer, M. (1969). Frog, where are you? New York: Dial.

Milch-Reich, S., Campbell, S.B., Pelham Jr., W.E., Connelly, L.M., \& Geva, D. (1999). Developmental and individual differences in children's online representations of dynamic social events. Child Development, 70, 413-431.

Milich, R., Balentine, A., \& Lynam, D.R. (2001). ADHD combined type and ADHD 
predominantly inattentive type are distinct and unrelated disorders. Clinical Psychology: Science and Practice, 8(4), 463-488.

Milich, R., Lorch, E.P., \& Berthiaume, K. (2005). Story comprehension in children with ADHD: Research findings and treatment implications. In M.P. Larimer (Ed.), Attention Deficit Hyperactivity Disorder Research (pp. 111-137). Hauppauge, NY: Nova Sciences.

Nezworski, T., Stein, N.L., \& Trabasso, T. (1982). Story structure versus content in children's recall. Journal of Verbal Learning and Verbal Behavior, 21, 196-206.

Nigg, J.T. (2001). Is ADHD a disinhibitory disorder? Psychological Bulletin, 127, 571598.

Nigg, J.T., Blaskey, L., Huang-Pollack, C., \& Rappley, M.D. (2002). Neuropsychological executive functions and DSM-IV subtypes. Journal of the American Academy of Child and Adolescent Psychiatry, 41, 59-66.

O’Brien, E.J., \& Myers, J.L. (1987). The role of causal connections in the retrieval of text. Memory and Cognition, 15, 419-427.

Pennington, B.F., Grossier, D., \& Welsh, M.C. (1993). Contrasting cognitive deficits in attention deficit disorder versus reading disability. Developmental Psychology, 29, 511-523.

Purvis, K.L., \& Tannock, R. (2000). Phonological processing, not inhibitory control, differentiates ADHD and reading disability. Journal of the American Academy of Child and Adolescent Psychiatry, 39, 485-494.

Quay, H.C. (1988). The behavioral reward and inhibition systems in childhood behavior disorders. In L.M. Bloomingdale (Ed.), Attention deficit disorder III: New research in treatment, psychopharmacology, and attention (pp. 176-186). New York: Pergamon.

Renz, K., Lorch, E.P., Milich, R., Lemberger, C., Bodner, A., \& Welsh, R. (2003). Online story representation in boys with attention deficit hyperactivity disorder. Journal of 
Abnormal Child Psychology, 31, 93-104.

Rosenthal, R., \& Rosnow, R.L. (1991). Essentials of behavioral research: Methods and data analysis ( $2^{\text {nd }}$ ed.). New York, McGraw Hill.

Schachar, R., \& Logan, G.D. (1990). Impulsivity and inhibitory control in normal development and childhood psychopathology. Developmental Psychology, 26, 710-720.

Semrud-Clikeman, M., Biederman, J., Sprich-Buckminster, S., Lehman, B.K., Faraone, S., \& Norman, D. (1992). Comorbidity between ADDH and learning disability: A review and report in a clinically referred sample. Journal of the American Academy of Child and Adolescent Psychiatry, 31, 439-448.

Trabasso, T., \& Sperry, L.L. (1985). Causal relatedness and importance of story events. Journal of Memory and Learning, 24, 595-611.

Trabasso, T., Stein, N.L., Rodkin, P.C., Munger, M.P., \& Baughn, C.R. (1992). Knowledge of goals and plans in the online narration of events. Cognitive Development, 7, 133170.

Trabasso, T., \& van den Broek, P. (1985). Causal thinking and the representation of narrative events. Journal of Memory and Language, 24, 612-630.

van den Broek, P. (1989). Causal reasoning and inference- making in judging the importance of story statements. Child Development, 60, 286-297.

Wagner, R.K., \& Torgesen, J.K. (1987). The nature of phonological processing and its causal role in the acquisition of reading skills. Psychological Bulletin, 101, 192-212.

Wechsler, D. (1991). WISC-III manual. Harcourt Brace \& Company: San Antonio, TX. 
Author Note

Kate Flory, Department of Psychology, University of South Carolina, Columbia, SC.

Richard Milich, Elizabeth P. Lorch, Angela N. Hayden, and Chandra Strange, Department of

Psychology, University of Kentucky, Lexington, KY. Richard Welsh, Department of Psychiatry, University of Kentucky, Lexington, KY.

This research was funded by grant \#MH47386 from the National Institute of Mental

Health. The authors wish to acknowledge the assistance of Mark Fillmore and Kristen

Berthiaume in the completion of this study.

Correspondence concerning this article should be addressed to Kate Flory at the University of South Carolina, Department of Psychology, Barnwell College, Columbia, SC

29208; Email: floryk@gwm.sc.edu; Phone: 803-777-4304; Fax: 803-777-9558. 


\section{Footnotes}

${ }^{1}$ We chose to utilize a narrow conceptualization of EF in our study, because a broad view of this core deficit would include aspects of inattention and disinhibition. Such a broad conceptualization would overlap with the other core deficits under investigation and make interpretation of results more difficult.

${ }^{2}$ Significant group differences in failing to inhibit responses were noted only for the two stop signals presented closest to the go stimuli, with the children with ADHD making more inhibitory errors. The difficulty all children experienced in inhibiting responses to the three stop signals furthest from the go stimuli appeared to preclude significant group differences on these measures, although there was a trend for the children with ADHD to make more inhibitory errors. Thus, we chose to include only the first two stop signals in the disinhibition composite. 
Table 1.

Group Means (and Standard Deviations) for Demographic and Diagnostic Factors.

Factor

Ethnicity

White $(\%)$

African-American (\%)

Other $(\%)$

Gender (\% boys)

Age (in years)

Mother's education $^{\mathrm{a}}$

Father's education $^{\mathrm{a}}$

ADHD symptoms ${ }^{b}$

ODD symptoms ${ }^{\mathrm{b}}$

CBCL Attention problems ${ }^{\mathrm{c}}$

CBCL Internalizing problems ${ }^{c}$

CBCL Externalizing problems ${ }^{c}$
76

20

4

80

$8.47(.85)$

$3.00(1.32)$

$2.78(1.61)$

$12.94(2.67)$

$3.26(2.35)$

$10.83(3.27)$

$12.00(8.33)$

20.74 (11.24)
92

4

4

64

$8.38(1.00)$

$4.30(1.37)$

$4.52(1.70)$

$.37(.79)$

$.31(.74)$

$1.24(1.60)$

$4.04(4.07)$

$5.15(4.84)$

Note: $\quad{ }^{a}$ Scale for mother's and father's education: $1=$ did not finish HS, 2 = HS diploma or GED, 3 = some college, 4 = 4-year college degree, $5=$ some graduate school, $6=\mathrm{MA} / \mathrm{MS}$ degree, $7=$ doctorate or equivalent.

${ }^{\mathrm{b}}$ As assessed by the $D S M-I V$ parent semi-structured interview.

'Taken from the Child Behavior Checklist (CBCL; Achenbach, 1991). 
Table 2.

Group Means (and Standard Deviations) for Story Coding Categories.

\begin{tabular}{|c|c|c|}
\hline Category & ADHD & Non-Referred \\
\hline Total clauses & $52.51(17.41)$ & $51.51(14.99)$ \\
\hline Initiating event ${ }^{\mathrm{a}}$ & $.63(.49)$ & $.84(.34)$ \\
\hline \multicolumn{3}{|l|}{ Attempts } \\
\hline Unlinked & $1.46(1.41)$ & $1.78(1.23)$ \\
\hline Linked & $2.66(1.49)$ & $3.04(1.42)$ \\
\hline Specific linked & $2.00(1.74)$ & $2.40(1.80)$ \\
\hline \multicolumn{3}{|l|}{ Outcomes } \\
\hline Negative & $2.11(1.48)$ & $2.44(1.22)$ \\
\hline Positive $^{\mathrm{a}}$ & $.61(.48)$ & $.78(.39)$ \\
\hline \multicolumn{3}{|c|}{ Goal-Attempt-Outcome (GAO) } \\
\hline Sequences & $2.71(1.55)$ & $3.21(1.34)$ \\
\hline Goal completion ${ }^{\mathrm{a}}$ & $.43(.50)$ & $.58(.49)$ \\
\hline \multicolumn{3}{|l|}{ Errors } \\
\hline Within-clause & $11.16(9.82)$ & $7.51(6.56)$ \\
\hline Whole clause & $1.74(3.06)$ & $.72(1.00)$ \\
\hline Repetition & $1.41(1.96)$ & $.79(1.07)$ \\
\hline
\end{tabular}

Note: $\quad{ }^{\mathrm{a}}$ Variables that were collected and coded as 0 (absent) or 1 (present). 
Table 3.

Results from Mediation Analyses.

Mediating Path

$z_{\alpha}$

$z_{\beta}$

$z_{\alpha} z_{\beta}$

Reduction

Diagnostic Group $\rightarrow$ Mediator $\rightarrow$ Initiating Event

Planning/working memory
Inattention
Disinhibition
Phonological processing
Verbal skills

$\begin{array}{llll}.82 & -1.64 & -1.34 & 33 \% \\ 2.37 & -1.67 & -3.96^{*} & 62 \% \\ -.26 & .78 & -.20 & 20 \% \\ -1.75 & .33 & -.58 & 45 \% \\ -2.50 & 1.92 & -4.80^{*} & 63 \%\end{array}$

Diagnostic Group $\rightarrow$ Mediator $\rightarrow$ Positive Outcome

Planning/working memory

.82

Inattention

2.37

1.23

1.01

Disinhibition

$-.26$

$-1.00$

$-2.37 *$

$34 \%$

Phonological processing

$-1.75$

.62

$-.16$

Verbal skills

$-2.50$

1.64

$-2.87 *$

$57 \%$

.38

$-.95$

$29 \%$

Diagnostic Group $\rightarrow$ Mediator $\rightarrow$ GAO Sequences

Planning/working memory

.82

$-1.13$

$-.93$

$41 \%$

Inattention

2.37

$-1.10$

$-2.61^{*}$

$58 \%$

Disinhibition

$-.26$

$-.05$

.01

$15 \%$

Phonological processing

$-1.75$

.43

$-.75$

$99 \%$

Verbal skills

$-2.50$

.69

$-1.73$

$81 \%$

Diagnostic Group $\rightarrow$ Mediator $\rightarrow$ Goal Completion

$\begin{array}{lllll}\text { Planning/working memory } & .82 & .33 & .27 & - \\ \text { Inattention } & 2.37 & -1.33 & -3.15^{*} & 63 \% \\ \text { Disinhibition } & -.26 & .58 & -.15 & - \\ \text { Phonological processing } & -1.75 & 1.31 & -2.29^{*} & 39 \% \\ \text { Verbal skills } & -2.50 & -1.25 & 3.13^{*} & - \\ \text { stic Group } \rightarrow \text { Mediator } \rightarrow \text { Within-Clause Errors } & & & \\ \text { Planning/working memory } & .82 & -.12 & -.10 & 24 \% \\ \text { Inattention } & 2.37 & 2.10 & 4.98^{*} & 61 \% \\ \text { Disinhibition } & -.26 & .86 & -.22 & 27 \% \\ \text { Phonological processing } & -1.75 & -.44 & .77 & 32 \% \\ \text { Verbal skills } & -2.50 & 1.73 & -4.33^{*} & -\end{array}$

Note: $\quad * p<.05, \mathrm{z}$-scores are from analyses with all mediators entered simultaneously, whereas percent reduction is from analyses with the mediators entered individually. 
Table 3 continued.

\begin{tabular}{lllll}
\hline Mediating Path & $z_{\alpha}$ & $z_{\beta}$ & $z_{\alpha} z_{\beta}$ & Reduction \\
\hline Diagnostic Group $\rightarrow$ Mediator $\rightarrow$ Whole-Clause Errors & & & & \\
Planning/working memory & .82 & .77 & .63 & $23 \%$ \\
Inattention & 2.37 & .89 & 2.11 & $36 \%$ \\
Disinhibition & -.26 & -.20 & .05 & $11 \%$ \\
Phonological processing & -1.75 & -.08 & .14 & $32 \%$ \\
Verbal skills & -2.50 & -.83 & 2.08 & $39 \%$ \\
Diagnostic Group $\rightarrow$ Mediator $\rightarrow$ Repetition Errors & & & & \\
Planning/working memory & .82 & -1.09 & -.89 & - \\
Inattention & 2.37 & -.30 & -.71 & - \\
Disinhibition & -.26 & 1.03 & -.27 & $16 \%$ \\
Phonological processing & -1.75 & -.56 & .98 & $15 \%$ \\
Verbal skills & -2.50 & .10 & -.25 & $12 \%$ \\
\hline
\end{tabular}

Note: $\quad * p<.05$, z-scores are from analyses with all mediators entered simultaneously, whereas percent reduction is from analyses with the mediators entered individually. 